\title{
Predictors of Outcome in 216 Subjects With ARDS Treated With Inhaled Epoprostenol
}

\author{
Jose Pacheco MD, Heather Arnold PharmD, Lee Skrupky PharmD, Peggy Watts MSc RRT, \\ Scott T Micek PharmD, and Marin H Kollef MD
}

\begin{abstract}
BACKGROUND: ARDS is an important cause of respiratory failure and continues to be associated with a high mortality rate. Numerous therapeutic interventions have been employed to improve patient outcomes, including inhaled epoprostenol. METHODS: We examined subjects with ARDS treated with epoprostenol. We compared hospital survivors with nonsurvivors to identify predictors of mortality. RESULTS: Among the cohort $(n=216)$, there were $80(37 \%)$ hospital survivors and $136(63 \%)$ hospital nonsurvivors. Logistic regression revealed 5 variables associated with hospital mortality: trauma as the etiology for ARDS (adjusted odds ratio [AOR] 0.09, 95\% CI 0.04-0.22, $P=.006$ ), presence of both pulmonary and nonpulmonary sources of sepsis (AOR 3.06, 95\% CI 1.98-4.74, $P=.01$ ), an international normalized ratio of $>1.5$ (AOR 3.15, 95\% CI 2.19-4.54, $P=.002$ ), body mass index (1-unit increments, AOR 0.95, 95\% CI 0.936-0.965, $P=.001$ ), and an incremental change in $\mathrm{P}_{\mathrm{aO}}{ }_{2} / \mathrm{F}_{\mathrm{IO}_{2}}$ during the first $24 \mathrm{~h}$ of treatment with epoprostenol (AOR 0.99, 95\% CI 0.988-0.994, $P=.002$ ). An analysis for 90-d mortality identified the same predictors, with the addition of cumulative fluid balance during treatment with epoprostenol of $>4 \mathrm{~L}$ also being an independent predictor (AOR 2.36, 95\% CI 1.66-3.37, $P=.02$ ). CONCLUSIONS: Although the use of epoprostenol in ARDS remains a therapeutic challenge, we were able to identify predictors of mortality for this important cohort of patients. These predictor variables could be employed in the design of future trials of epoprostenol in ARDS. Key words: acute respiratory distress syndrome; ARDS; epoprostenol; outcome. [Respir Care 2014;59(8):1178-1185. (C) 2014 Daedalus Enterprises]
\end{abstract}

\section{Introduction}

Significant investigation and health-care dollars have been directed toward improving outcomes in ARDS. Despite these efforts, morbidity and mortality remain unac-

Drs Pacheco and Kollef are affiliated with the Division of Pulmonary and Critical Care, Washington University School of Medicine, St. Louis, Missouri. Drs Arnold and Skrupky are affiliated with the Department of Pharmacy, and Ms Watts is affiliated with the Department of Respiratory Care, Barnes-Jewish Hospital, St. Louis, Missouri. Dr Micek is affiliated with the St. Louis College of Pharmacy, St. Louis, Missouri.

Dr Kollef was supported by the Barnes-Jewish Hospital Foundation. The other authors have disclosed no conflicts of interest.

Correspondence: Marin H Kollef MD, Division of Pulmonary and Critical Care Medicine, Washington University School of Medicine, 660 South Euclid Avenue, Campus Box 8052, St. Louis, MO 63110. E-mail: mkollef@dom.wustl.edu.

DOI: $10.4187 /$ respcare.02939 ceptably high, with reported hospital mortality rates of $>30 \% .^{1,2}$ Only the use of low tidal volumes has consistently shown mortality benefit in trials examining ARDS. ${ }^{3-5}$ The high mortality associated with ARDS has led to the evaluation and use of salvage therapies, including pulmonary vasodilators, corticosteroids, surfactants, prone positioning, neuromuscular blockers, alternative modes of

SeE the Related Editorial on Page 1312

mechanical ventilation, and extracorporeal membrane oxygenation (ECMO). ${ }^{6-10}$ The utilization of these salvage modalities has traditionally been based on local factors such as availability of the technique and experience of the clinicians caring for patients with ARDS. Inhaled epoprostenol is employed as a rescue therapy for ARDS, and its use is associated with improved oxygenation, reduced shunt, and decreased pulmonary artery pressures. ${ }^{11} \mathrm{We}$ 
hypothesized that specific subgroups of patients with ARDS receiving rescue therapy with inhaled epoprostenol may be more likely to survive or die. Therefore, we set out to identify predictors of hospital mortality and 90-d mortality among patients with ARDS treated with inhaled epoprostenol.

\section{Methods}

We conducted a retrospective review of all patients admitted with ARDS to a large, urban, tertiary-care teaching hospital (Washington University School of Medicine and Barnes-Jewish Hospital in St. Louis, Missouri). We focused on the time period from January 1, 2004, to June 30, 2012. The study was approved by the Washington University School of Medicine Human Studies Committee and informed consent was waived (Protocol No. 201212017).

\section{Subjects}

To be included in the study population, subjects had to meet the Berlin criteria for ARDS, including the criteria for $\mathrm{P}_{\mathrm{aO}_{2}} / \mathrm{F}_{\mathrm{IO}_{2}}$ and PEEP. ${ }^{12}$ More specifically, the Berlin Definition for ARDS requires the presence of (1) onset within 1 week of a known clinical insult or new or worsening respiratory symptoms; (2) bilateral opacities not fully explained by effusions, lobar/lung collapse, or nodules; (3) respiratory failure not fully explained by cardiac failure or fluid overload; and (4) oxygenation impairment (minimum impairment of $200 \mathrm{~mm} \mathrm{Hg}<\mathrm{P}_{\mathrm{aO}_{2}} / \mathrm{F}_{\mathrm{IO}_{2}}$ $\leq 300 \mathrm{~mm} \mathrm{Hg}$ with PEEP $\geq 5 \mathrm{~cm} \mathrm{H}_{2} \mathrm{O}$ ). Moreover, subjects had to receive inhaled epoprostenol for the treatment of ARDS to be eligible for study inclusion. One investigator (JP) reviewed all the cases and imaging studies to confirm that subjects met these inclusion criteria.

\section{Ventilation Modes}

The primary mode of ventilation for ARDS at BarnesJewish Hospital during this study period was volume control continuous mandatory ventilation using a tidal volume of $6-8 \mathrm{~mL} / \mathrm{kg}$ based on predicted body weight (PB840 ventilator, Covidien, Mansfield, Massachusetts). Airway pressure release ventilation via the bi-level mode on the PB840 ventilator was also used during the study period at the request of the treating physicians.

\section{Inhaled Epoprostenol Administration}

Inhaled epoprostenol was provided to subjects with ARDS after a physician entered the order via a standardized electronic ordering system for inhaled epoprostenol (Flolan, epoprostenol sodium, GlaxoSmithKline, Philadel-

\section{QUICK LOOK}

\section{Current knowledge}

ARDS is characterized by ventilation/perfusion mismatching and hypoxemia. Inhaled vasodilators, including nitric oxide and aerosolized epoprostenol, have been used to improve oxygenation, but neither has been shown to improve survival.

\section{What this paper contributes to our knowledge}

This retrospective review of subjects with ARDS treated with aerosolized epoprostenol demonstrated a 90-d mortality rate of $68 \%$. Subjects with trauma, greater body mass index, and greater improvements in oxygenation had an improved hospital and 90-d survival. Subjects with sepsis and an international normalized ratio of $>1.5$ had an increased mortality.

phia, Pennsylvania), starting at a dose of $20,000 \mathrm{ng} / \mathrm{mL}$. Respiratory care practitioners administered the inhaled epoprostenol utilizing an infusion pump and a low-flow jet nebulizer (Mini-HEART, Medline Industries, Mundelein, Illinois) that was in line with the ventilator circuit. The syringes employed for inhaled epoprostenol were carefully labeled to indicate that they were to be used only via the inhalational route. The dose of epoprostenol was weaned as the subject responded to the administered therapy. The Mini-HEART nebulizer was charged with a volume of $15 \mathrm{~mL}$ of epoprostenol. The infusion rate for epoprostenol was $8 \mathrm{~mL} / \mathrm{h}$ into the Mini-HEART nebulizer. The respiratory therapist connected the oxygen tubing from the nebulizer to an oxygen flow meter and set the flow at 2-3 L/ $\min$. At this flow, the nebulizer output was $\sim 8 \mathrm{~mL} / \mathrm{h}$. The flow of gas to the nebulizer may need adjustment to maintain $15 \mathrm{~mL}$ of the epoprostenol solution in the reservoir at all times. Increasing or decreasing the gas flow changed the nebulizer output. Nebulizer flow must not exceed $3 \mathrm{~L} /$ min.

\section{End Points}

The primary end point was hospital mortality. We also examined $90-\mathrm{d}$ mortality as a secondary end point.

\section{Definitions and Covariates}

Fluid balance was determined by assessing the electronic medical records for 2 time frames: during hospitalization before the start of epoprostenol and during the infusion period for epoprostenol. Appropriate empiric antimicrobial therapy was defined as antimicrobials given 
within $24 \mathrm{~h}$ of the onset of signs and symptoms of infection that were active against the pathogen(s) associated with infection based on in vitro susceptibility testing. ${ }^{13}$ Severity of illness was assessed by Acute Physiology and Chronic Health Evaluation II and Sequential Organ Failure Assessment scores. ${ }^{14,15}$ Pulmonary sources of sepsis included pneumonia, lung abscess, and empyema. Nonpulmonary sources of sepsis included bacteremia (not related to a pulmonary source of infection), intra-abdominal infection, skin or wound infection, and urinary tract infections. In addition, we recorded information regarding subject demographics (ie, age, gender, race) and processes of care (use of corticosteroids, neuromuscular blocking agents, administration of nitric oxide).

\section{Statistics}

We compared hospital survivors with nonsurvivors. To compare categorical variables, we utilized the chi-square test and the Fisher exact test. For continuous variables, we employed either the Student $t$ test or nonparametric tests, as appropriate. All tests were 2-tailed, and we assumed statistical significance if $P<.05$.

To identify factors independently associated with hospital mortality, we relied on logistic regression. Variables significant at the .15 level that were considered biologically relevant were entered into the regression model. We assessed variables for co-linearity and explored goodness of fit based on the Hosmer-Lemeshow test. Potential interactions were examined with the Breslow-Day test. Analyses were performed using SPSS 11.0 (SPSS, Chicago, Illinois).

\section{Results}

The entire cohort included 216 subjects. There were $80(37 \%)$ hospital survivors and $136(63 \%)$ hospital nonsurvivors. Table 1 shows the clinical characteristics according to hospital survival. Process-of-care variables are summarized in Table 2. The mean and median epoprostenol doses administered during the first $24 \mathrm{~h}$ of therapy and at the end of therapy were significantly greater for hospital nonsurvivors, although the duration of epoprostenol administration was shorter for hospital nonsurvivors. Epoprostenol-free days during the first $72 \mathrm{~h}$ of mechanical ventilation were statistically greater among survivors, although the absolute difference was small $(<1 \mathrm{~d})$. Stressdose administration of corticosteroids was statistically greater among nonsurvivors, as was the use of norepinephrine and epinephrine as vasoactive agents. Cumulative fluid balance was greater during the period of hospitalization before epoprostenol administration and during epoprostenol treatment, only achieving statistical significance during the treatment phase. Figure 1 shows the total cumula- tive fluid balance for survivors and nonsurvivors up to the end of epoprostenol treatment (median [interquartile range] of 7.6 L [2.3-15.9 L] for survivors and 12.5 L [6.7-23.2 L] for nonsurvivors, $P=.001) . \mathrm{P}_{\mathrm{aO}_{2}} / \mathrm{F}_{\mathrm{IO}_{2}}$ was significantly greater in survivors compared with nonsurvivors during the initiation, first $24 \mathrm{~h}$, and termination of epoprostenol treatment (Fig. 2). ICU stay was significantly longer for survivors compared with nonsurvivors $(23.6 \pm 14.0$ vs $14.2 \pm 13.9 \mathrm{~d}, P<.001)$.

Logistic regression (Table 3 ) identified 5 variables independently associated with hospital mortality. Lower risk of hospital mortality was associated with trauma as the etiology for ARDS, increasing body mass index (1-unit increments), and an incremental change in $\mathrm{P}_{\mathrm{aO}_{2}} / \mathrm{F}_{\mathrm{IO}_{2}}$ during the first $24 \mathrm{~h}$ of treatment with epoprostenol, whereas greater risk of hospital mortality was associated with presence of both pulmonary and nonpulmonary sources of sepsis and an international normalized ratio of $>1.5$.

There were 68 (31.5\%) 90-d survivors and 148 (68.5\%) 90-d nonsurvivors. Logistic regression identified 6 variables independently associated with 90-d mortality. Lower risk of hospital mortality was associated with trauma as the etiology for ARDS, increasing body mass index (1-unit increments), and an incremental change in $\mathrm{P}_{\mathrm{aO}} / \mathrm{F}_{\mathrm{IO}_{2}}$ during the first $24 \mathrm{~h}$ of treatment with epoprostenol, whereas greater risk of hospital mortality was associated with presence of both pulmonary and nonpulmonary sources of sepsis, an international normalized ratio of $>1.5$, and cumulative fluid balance during treatment with epoprostenol of $>4 \mathrm{~L}$ (Table 4).

\section{Discussion}

This retrospective analysis of subjects with ARDS treated with inhaled epoprostenol confirms the high risk of mortality in this population. Although ARDS patients with a greater risk of mortality may be more likely to be subjected to treatment with salvage therapies, they may also be less likely to respond to such treatments. The identification of patients who are unlikely to survive such interventions could improve the overall utilization of rescue treatments. Moreover, the unique factors identified as predictors of outcome could be employed in the design of future clinical trials of epoprostenol for ARDS by standardizing supportive therapies such as fluid administration and ensuring that balance is achieved in important baseline characteristics such as body weight, ARDS etiology, and causes of sepsis.

Epoprostenol is the inhaled pulmonary vasodilator primarily employed at Barnes-Jewish Hospital for patients with ARDS, chiefly due to the lower cost associated with its use. Inhaled nitric oxide is less commonly employed but has more clinical trials examining its use. In randomized clinical trials, inhaled nitric oxide was associated with 
Predictors of Outcome in ARDS With Inhaled Epoprostenol

Table 1. Subjects Characteristics

\begin{tabular}{|c|c|c|c|}
\hline Characteristic & $\begin{array}{l}\text { Hospital Survivors } \\
\qquad(n=80)\end{array}$ & $\begin{array}{l}\text { Hospital Nonsurvivors } \\
\qquad(n=136)\end{array}$ & $P$ \\
\hline Age, mean $\pm \mathrm{SD}, \mathrm{y}$ & $46.7 \pm 17.4$ & $53.2 \pm 16.2$ & .006 \\
\hline \multicolumn{4}{|l|}{ Gender, $n(\%)$} \\
\hline Male & $42(52.5)$ & $74(54.4)$ & \multirow[t]{2}{*}{.79} \\
\hline Female & $38(47.5)$ & $62(45.6)$ & \\
\hline $\mathrm{BMI}$, mean $\pm \mathrm{SD}$ (median $[\mathrm{IQR}]), \mathrm{kg} / \mathrm{m}^{2}$ & $34.1 \pm 14.3(31.8[24.3-40.2])$ & $27.8 \pm 9.5(25.8[21.6-32.2])$ & $<.001$ \\
\hline \multicolumn{4}{|l|}{ Comorbidities, $n(\%)$} \\
\hline Underlying malignancy & $3(3.8)$ & $17(12.5)$ & .05 \\
\hline End-stage renal disease & $3(3.8)$ & $6(4.4)$ & $>.99$ \\
\hline Cirrhosis & $6(7.5)$ & $19(14.0)$ & .15 \\
\hline HIV & $0(0.0)$ & $4(2.9)$ & .30 \\
\hline Congestive heart failure & $0(0.0)$ & $1(0.7)$ & $>.99$ \\
\hline Dementia & $0(0.0)$ & $1(0.7)$ & $>.99$ \\
\hline Chronic lung disease & $6(7.5)$ & $10(7.4)$ & .97 \\
\hline Elevated INR & $23(28.8)$ & $64(47.1)$ & .008 \\
\hline Thrombocytopenia & $3(3.8)$ & $19(14.0)$ & .02 \\
\hline Lung transplant & $3(3.8)$ & $2(1.5)$ & .36 \\
\hline SOFA score, mean \pm SD & $6.9 \pm 2.8$ & $8.7 \pm 3.9$ & .05 \\
\hline APACHE II score, mean $\pm \mathrm{SD}$ & $15.6 \pm 6.2$ & $16.6 \pm 5.4$ & .21 \\
\hline \multicolumn{4}{|l|}{ ARDS etiology, $n(\%)$} \\
\hline Primary & $63(78.8)$ & $109(80.1)$ & .81 \\
\hline Secondary & $33(41.3)$ & $68(50.0)$ & .21 \\
\hline Both & $19(23.8)$ & $49(36.0)$ & .06 \\
\hline Undetermined & $3(3.8)$ & $8(5.9)$ & .75 \\
\hline Pneumonia & $25(31.3)$ & $53(39.0)$ & .25 \\
\hline Aspiration & $10(12.5)$ & $3(2.2)$ & .005 \\
\hline Nonpulmonary sepsis & $6(7.5)$ & $15(11.0)$ & .40 \\
\hline Pulmonary and nonpulmonary sepsis & $9(11.3)$ & $45(33.1)$ & $<.001$ \\
\hline Trauma & $10(12.5)$ & $2(1.5)$ & .001 \\
\hline Influenza & $9(11.3)$ & $7(5.1)$ & .10 \\
\hline Myocardial infarction & $1(1.3)$ & $0(0.0)$ & .37 \\
\hline Pancreatitis & $0(0.0)$ & $3(2.2)$ & .30 \\
\hline Leukostasis & $1(1.3)$ & $0(0.0)$ & .37 \\
\hline Acute chest syndrome & $1(1.3)$ & $0(0.0)$ & .37 \\
\hline Smoke inhalation & $2(2.5)$ & $0(0.0)$ & .14 \\
\hline Ehrlichiosis & $2(2.5)$ & $0(0.0)$ & .14 \\
\hline Hemophagocytic lymphohistiocytosis & $1(1.3)$ & $0(0.0)$ & .37 \\
\hline \multicolumn{4}{|l|}{$\mathrm{ICU}, n(\%)$} \\
\hline Medical & $37(46.3)$ & $80(58.8)$ & .07 \\
\hline Surgical/trauma & $29(36.3)$ & $27(19.9)$ & .008 \\
\hline Cardiac & $3(3.8)$ & $3(2.2)$ & .67 \\
\hline Cardiothoracic surgery & $8(10.0)$ & $10(7.4)$ & .50 \\
\hline Oncology/bone marrow transplant & $0(0.0)$ & $16(11.8)$ & .001 \\
\hline Neurologic/neurosurgical & $4(5.0)$ & $4(2.9)$ & .47 \\
\hline $\begin{array}{l}\text { BMI }=\text { body mass index } \\
\text { IQR = interquartile range } \\
\text { HIV = human immunodeficiency virus } \\
\text { SOFA = Sequential Organ Failure Assessment } \\
\text { APACHE = Acute Physiology and Chronic Health Eval } \\
\text { INR = international normalized ratio }\end{array}$ & & & \\
\hline
\end{tabular}

a transient improvement in oxygenation in adults with ARDS without any survival benefit. ${ }^{16-20}$ In a systematic review and meta-analysis of patients with acute lung injury or ARDS from 12 trials, inhaled nitric oxide was associated with modest improvements in oxygenation (13\% increase in $\mathrm{P}_{\mathrm{aO}_{2}} / \mathrm{F}_{\mathrm{IO}_{2}}$ until days 3-4 of administration), no effect on mean pulmonary artery pressure, and no effect on survival or duration of mechanical ventilation. ${ }^{21}$ 
Predictors of Outcome in ARDS With Inhaled Epoprostenol

Table 2. Process-of-Care Variables

\begin{tabular}{|c|c|c|c|}
\hline Variable & Hospital Survivors $(n=80)$ & Hospital Nonsurvivors $(n=136)$ & $P$ \\
\hline $\begin{array}{l}\text { Time of ARDS to inhaled epoprostenol, } \\
\text { mean } \pm \mathrm{SD}(\text { median }[\mathrm{IQR}]), \mathrm{h}\end{array}$ & $55.2 \pm 76.8(28.9[11.2-50.3])$ & $69.6 \pm 93.8(32.8[12.681 .6])$ & .24 \\
\hline $\begin{array}{l}\text { Mean epoprostenol dose during first } 24 \mathrm{~h}, \\
\text { mean } \pm \mathrm{SD}(\text { median }[\mathrm{IQR}]), \mathrm{ng} / \mathrm{kg} / \mathrm{min}\end{array}$ & $26.5 \pm 10.3(25.9[18.8-32.9])$ & $34.9 \pm 12.4(34.3[25.4-42.3])$ & $<.001$ \\
\hline $\begin{array}{l}\text { Mean epoprostenol dose at end of therapy, } \\
\text { mean } \pm \mathrm{SD}(\text { median }[\mathrm{IQR}]), \mathrm{ng} / \mathrm{kg} / \mathrm{min}\end{array}$ & $13.3 \pm 10.9(9.1[6.0-15.1])$ & $32.6 \pm 14.7(32.2[22.9-42.2])$ & $<.001$ \\
\hline $\begin{array}{l}\text { Duration of epoprostenol, mean } \pm \mathrm{SD} \\
\quad(\text { median }[\mathrm{IQR}]), \mathrm{h}\end{array}$ & $118.5 \pm 85.1(97.7[58.8-152.8])$ & $99.1 \pm 108.7(61[19.2-137.0])$ & .002 \\
\hline $\begin{array}{l}\text { Epoprostenol-free days, mean } \pm \text { SD } \\
\quad(\text { median }[\mathrm{IQR}])\end{array}$ & $0.7 \pm 0.9(0.3[0.0-1.2])$ & $0.4 \pm 0.7(0.0[0.0-0.6])$ & .002 \\
\hline Nitric oxide, $n(\%)$ & $9(11.3)$ & $16(11.8)$ & .91 \\
\hline \multicolumn{4}{|l|}{ Stress dose steroids, $n(\%)$} \\
\hline Period 1 & $11(13.8)$ & $52(38.2)$ & $<.001$ \\
\hline Period 2 & $41(51.3)$ & $90(66.2)$ & .03 \\
\hline \multicolumn{4}{|l|}{ Neuromuscular blocker, $n(\%)$} \\
\hline Period 1 & $19(23.8)$ & $21(15.4)$ & .13 \\
\hline Period 2 & $32(40.0)$ & $56(41.2)$ & .87 \\
\hline \multicolumn{4}{|l|}{ Vasoactive agent, $n(\%)$} \\
\hline \multicolumn{4}{|l|}{ Period 1} \\
\hline Norepinephrine & $44(55.0)$ & $91(66.9)$ & .08 \\
\hline Vasopressin & $10(12.5)$ & $25(18.4)$ & .28 \\
\hline Epinephrine & $2(2.5)$ & $4(2.9)$ & $>.99$ \\
\hline Dobutamine & $5(6.3)$ & $5(3.7)$ & .39 \\
\hline Dopamine & $2(2.5)$ & $7(5.1)$ & .49 \\
\hline Phenylephrine & $13(16.3)$ & $14(10.3)$ & .20 \\
\hline \multicolumn{4}{|l|}{ Period 2} \\
\hline Norepinephrine & $56(70.0)$ & $113(83.1)$ & .02 \\
\hline Vasopressin & $21(26.3)$ & $45(33.3)$ & .29 \\
\hline Epinephrine & $3(3.8)$ & $23(16.9)$ & .004 \\
\hline Dobutamine & $15(18.8)$ & $24(17.6)$ & .84 \\
\hline Dopamine & $4(5.0)$ & $12(8.8)$ & .42 \\
\hline Phenylephrine & $11(13.8)$ & $17(12.5)$ & .79 \\
\hline Milrinone during period 1 or $2, n(\%)$ & $0(0.0)$ & $1(0.7)$ & $>.99$ \\
\hline Appropriate antibiotic therapy, $n(\%)$ & $80(100.00)$ & $130(96.3)$ & .08 \\
\hline \multicolumn{4}{|l|}{$\begin{array}{l}\text { Cumulative fluid balance, mean } \pm \text { SD } \\
\text { (median }[\mathrm{IQR}]), \mathrm{L}\end{array}$} \\
\hline Period 1 & $6.74 \pm 9.4(3.7[0.1-933])$ & $9.3 \pm 13.8(5.9[1.2-11.9])$ & .12 \\
\hline Period 2 & $2.8 \pm 6.4(3.1[-0.7$ to 7.4$])$ & $8.7 \pm 22.6(4.4[1.2-9.7])$ & .002 \\
\hline \multicolumn{4}{|l|}{$\mathrm{P}_{\mathrm{aO}_{2}} / \mathrm{F}_{\mathrm{IO}_{2}}$, mean $\pm \mathrm{SD}($ median $[\mathrm{IQR}])$} \\
\hline Initiation of epoprostenol & $94.1 \pm 34.5(82.4[72.0-115.5])$ & $81.7 \pm 32.7(72.5[57.2-95.6])$ & .003 \\
\hline $\begin{array}{l}\text { Mean value during first } 24 \mathrm{~h} \text { of } \\
\text { epoprostenol }\end{array}$ & $148.0 \pm 65.0(128.5[94.0-197.5])$ & $119.7 \pm 58.2105 .5[78.6-142.8])$ & .001 \\
\hline Termination of epoprostenol & $254.3 \pm 123.0(220[181.3-312.3])$ & $142.7 \pm 102.2(103.0[67.0-185.8])$ & $<.001$ \\
\hline \multicolumn{4}{|c|}{$\begin{array}{l}\text { Period } 1 \text { is defined as prior to the start of the epoprostenol infusion, and period } 2 \text { is defined as during the epoprostenol infusion. } \\
\text { * During the first } 72 \mathrm{~h} \text { of mechanical ventilation } \\
\mathrm{IQR}=\text { interquartile range }\end{array}$} \\
\hline
\end{tabular}

Available clinical data suggest that epoprostenol and inhaled nitric oxide are associated with similar improvements in oxygenation and outcomes in patients with ARDS.6,22,23 However, available clinical trial data do not resolve the question of whether pulmonary vasodilators lead to any clinically important benefits in certain sub- groups of patients, such as those with severe hypoxemia not responding to conventional treatment. It is in this sense that pulmonary vasodilators are frequently used as a rescue therapy. Our experience with epoprostenol in ARDS suggests that groups of patients having either greater or lesser likelihood of survival can be identified. 


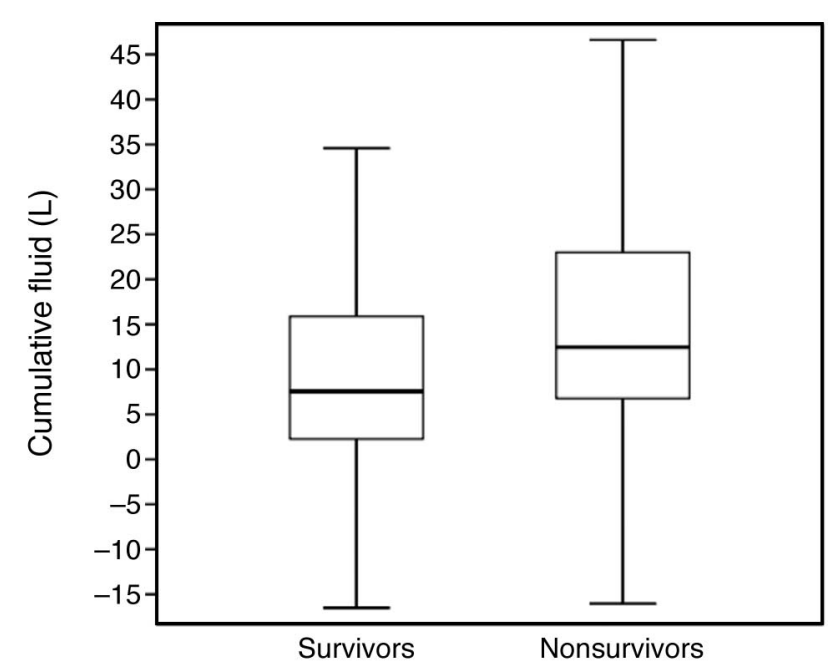

Fig. 1. Box plots depicting cumulative fluid balance up to the termination of epoprostenol for hospital survivors and nonsurvivors. The lines within the boxes represent the 50th percentile, the lines at the bottom and top of the boxes represent the 25th and 75th percentiles, and the whisker lines represent the 5th and 95th percentiles. $P=.001$.

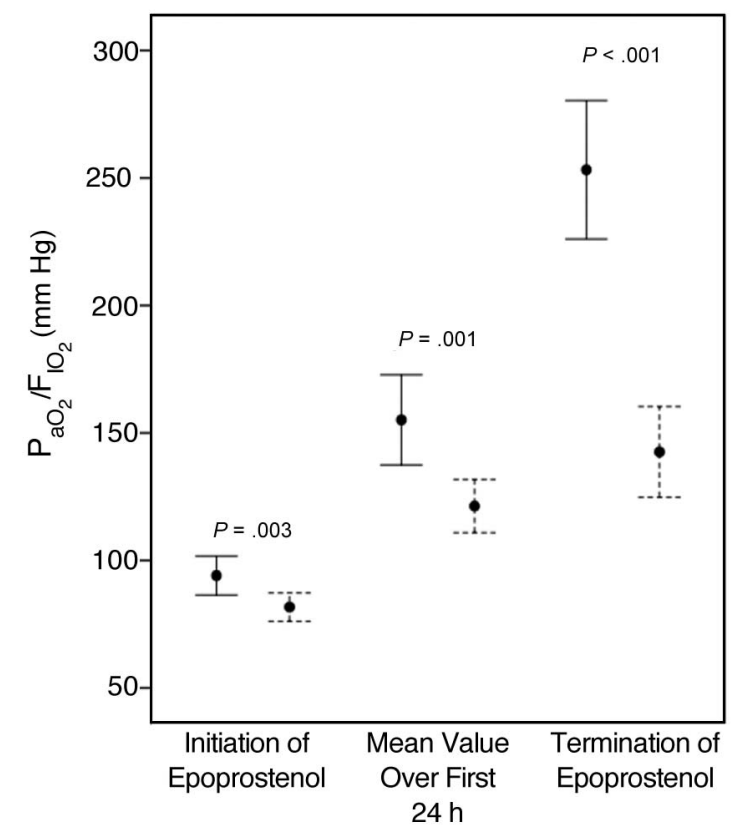

Fig. 2. Mean values $\pm 95 \%$ confidence intervals for $\mathrm{P}_{\mathrm{aO}_{2}} / \mathrm{F}_{\mathrm{IO}_{2}}$ in hospital survivors (solid bars) and nonsurvivors (hatched bars) at three distinct times.

Other authors have attempted to develop criteria aimed at identifying patients with ARDS who are more likely to have good outcomes associated with salvage therapies. Camporota et $\mathrm{al}^{24}$ examined subjects with ARDS receiving high-frequency oscillatory ventilation. Improvement in the $\mathrm{P}_{\mathrm{aO}_{2}} / \mathrm{F}_{\mathrm{IO}_{2}}$ of $>38 \%$ occurring at any time within the first
Table 3. Independent Factors Associated With Hospital Mortality

\begin{tabular}{lccc}
\hline \hline \multicolumn{1}{c}{ Variable } & $\begin{array}{c}\text { Adjusted } \\
\text { Odds Ratio }\end{array}$ & $95 \% \mathrm{CI}$ & $P$ \\
\hline $\mathrm{BMI}$ (1-unit increments) & 0.95 & $0.936-0.965$ & .001 \\
Trauma & 0.09 & $0.04-0.22$ & .006 \\
Pulmonary and nonpulmonary sepsis & 3.06 & $1.98-4.74$ & .01 \\
$\mathrm{INR} \geq 1.5$ & 3.15 & $2.19-4.54$ & .002 \\
$\mathrm{P}_{\mathrm{aO}} / \mathrm{F}_{\mathrm{IO}_{2}}$ increment (1-unit increments)* & 0.99 & $0.988-0.994$ & .002 \\
& & & \\
Hosmer-Lemeshow goodness of fit $(P=.96)^{*}$ Values indicate the difference between $\mathrm{P}_{\mathrm{aO} 2} / \mathrm{F}_{\mathrm{IO}_{2}}$ measured after 24 h of epoprostenol and at \\
baseline. Other covariates not listed had a $P$ value of $>.05$, including age, presence of \\
underlying malignancy, thrombocytopenia, Sequential Organ Failure Assessment score, \\
aspiration, ICU admission type, and cumulative fluid balance during treatment with \\
epoprostenol of $>4 \mathrm{~L}$. \\
BMI $=$ body mass index \\
INR = international normalized ratio \\
\end{tabular}

Table 4. Independent Factors Associated With 90-d Mortality

\begin{tabular}{|c|c|c|c|}
\hline Variable & $\begin{array}{l}\text { Adjusted } \\
\text { Odds Ratio }\end{array}$ & $95 \% \mathrm{CI}$ & $P$ \\
\hline BMI (1-unit increments) & 0.95 & $0.936-0.967$ & .001 \\
\hline Trauma & 0.13 & $0.06-0.28$ & .005 \\
\hline Pulmonary and nonpulmonary sepsis & 3.87 & $2.32-6.46$ & .008 \\
\hline $\mathrm{INR} \geq 1.5$ & 3.64 & $2.44-5.42$ & .00 \\
\hline $\mathrm{P}_{\mathrm{aO}_{2}} / \mathrm{F}_{\mathrm{IO}_{2}}$ increment (1-unit increments)* & 0.99 & $0.987-0.993$ & .00 \\
\hline $\begin{array}{l}\text { Cumulative fluid balance during } \\
\text { treatment with epoprostenol of }>4 \mathrm{~L}\end{array}$ & 2.36 & $1.66-3.37$ & .02 \\
\hline \multicolumn{4}{|c|}{$\begin{array}{l}\text { Hosmer-Lemeshow goodness of fit }(P=.80) \\
* \text { The values indicate the difference between } \mathrm{P}_{\mathrm{aO}} / \mathrm{F}_{\mathrm{IO}_{2}} \text { measured after } 24 \mathrm{~h} \text { of epoprostenol } \\
\text { and at baseline. Other covariates not listed had a } P \text { value of }>.05 \text {, including age, presence of } \\
\text { underlying malignancy, thrombocytopenia, Sequential Organ Failure Assessment score, } \\
\text { aspiration, and ICU admission type. } \\
\text { BMI = body mass index } \\
\mathrm{INR}=\text { international normalized ratio }\end{array}$} \\
\hline
\end{tabular}

$72 \mathrm{~h}$ was the best predictor of survival at $30 \mathrm{~d}$. Multivariate analysis showed that high-frequency oscillatory ventilation was more effective in younger subjects when instituted early and in subjects with milder respiratory acidosis. ${ }^{24}$ Pappalardo et al ${ }^{25}$ developed a score to predict survivors of ARDS associated with influenza A (H1N1) treated with ECMO. The predictor variables in their score included hospital stay before ECMO institution, bilirubin, creatinine, hematocrit, and mean arterial pressure. In a similar analysis of ARDS attributed to H1N1, Pham et al ${ }^{26}$ identified older age, higher lactate, and higher plateau pressures during ECMO as being associated with increased odds of ICU death for ECMO recipients and demonstrated no overall survival benefit with the use of ECMO. However, these types of outcome data provide an opportunity to design therapeutic intervention trials in ARDS targeting patient populations that may be more likely to demonstrate benefit. 
Our study is similar to that of Pham et al ${ }^{26}$ in identifying a process-of-care variable that was associated with excess mortality in ARDS subjects receiving a specific rescue therapy, namely greater fluid balance during the administration of epoprostenol compared with greater achieved plateau pressures in their study. Other investigators have also found associations between fluid balance and outcome in subjects with ARDS ${ }^{27,28}$ and those at risk for this syndrome. ${ }^{29,30}$ This has potentially important implications in terms of optimizing patient outcomes when inhaled vasodilator therapy or other rescue therapies are employed, especially in the context of a clinical trial. Our study is unique in identifying greater body mass index as a predictor of survival. Previous studies have shown that obesity is associated with the development of ARDS. ${ }^{31,32}$ However, a recent French study found the use of prone positioning to be safe in obese subjects, and prone positioning improved oxygenation more in obese subjects with ARDS than in non-obese subjects. ${ }^{33}$

Our study has several important limitations. First, it is retrospective and therefore prone to several forms of bias. We attempted to minimize the impact of this by confirming, through the use of multiple hospital databases, that all patients with ARDS who received therapy with inhaled epoprostenol were included in this analysis. Moreover, we had one investigator determine that each subject met the criteria for ARDS, including the radiographic criteria. Second, we did not track the use of airway pressure release ventilation within this study, nor did we track the use of prone positioning. Therefore, we could not determine whether the use of these salvage therapies influences the outcomes associated with epoprostenol use. Third, the data came from a single center, limiting its more general applicability. Fourth, in restricting the analysis to patients receiving inhaled epoprostenol as a rescue therapy, we may have skewed our findings by focusing on patients with more severe disease. This is supported by the high mortality $(>60 \%)$ and relatively low $\mathrm{P}_{\mathrm{aO}_{2}} / \mathrm{F}_{\mathrm{IO}_{2}}$ we observed. This limits the applicability of these data to patients with less severe disease. Finally, our sample size was somewhat limited. With a greater number of subjects, we could have employed differing approaches to modeling the risk for hospital and 90-d mortality and better validated the identified predictor variables.

Unfortunately, there are few randomized data regarding the use of inhaled epoprostenol for ARDS. ${ }^{34}$ Although we know that inhaled epoprostenol can improve oxygenation and reduce shunt ${ }^{11}$ in patients with ARDS, there are no compelling data that its routine use will improve survival. ${ }^{6,22,23,34}$ Moreover, there are virtually no data to guide clinicians in terms of which patients with ARDS are more likely to benefit from the administration of inhaled epoprostenol. Nevertheless, our findings suggest that the use of inhaled epoprostenol in patients with ARDS associated with trauma, greater body mass index, and more robust improvements in oxygenation is more likely to result in both hospital and 90-d survival.

In conclusion, patients receiving rescue therapies such as inhaled epoprostenol typically have a high risk for hospital and 90-d mortality. Although few potential rescue therapies for ARDS, including prone positioning and administration of neuromuscular blockers, ${ }^{8,33,35}$ have been shown to improve survival, it is likely that the use of rescue therapies will continue and even expand due to the high mortality associated with this syndrome and the lack of more definitive treatments. The identification of outcome predictors associated with the use of inhaled epoprostenol for ARDS may facilitate more accurate identification of patients who are unlikely to benefit from its administration. This could result in more focused and costeffective use of epoprostenol and improve future clinical trial design by allowing more balanced groups for comparison and improved inclusion and exclusion criteria to enhance detection of a therapeutic effect.

\section{REFERENCES}

1. Matthay MA, Ware LB, Zimmerman GA. The acute respiratory distress syndrome. J Clin Invest 2012;122(8):2731-2740.

2. Fanelli V, Vlachou A, Ghannadian S, Simonetti U, Slutsky AS, Zhang H. Acute respiratory distress syndrome: new definition, current and future therapeutic options. J Thorac Dis 2013;5(3):326-334.

3. The Acute Respiratory Distress Syndrome Network. Ventilation with lower tidal volumes as compared with traditional tidal volumes for acute lung injury and the acute respiratory distress syndrome. N Engl J Med 2000;342(18):1301-1308.

4. Amato MB, Barbas CS, Medeiros DM, Magaldi RB, Schettino GP, Lorenzi-Filho G, et al. Effect of a protective-ventilation strategy on mortality in the acute respiratory distress syndrome. N Engl J Med 1998;338(6):347-354.

5. Villar J, Kacmarek RM, Pérez-Méndez L, Aguirre-Jaime A. A high positive end-expiratory pressure, low tidal volume ventilatory strategy improves outcome in persistent acute respiratory distress syndrome: a randomized, controlled trial. Crit Care Med 2006;34(5): 1311-1318.

6. Walmrath D, Schneider T, Schermuly R, Olschewski H, Grimminger F, Seeger W. Direct comparison of inhaled nitric oxide and aerosolized prostacyclin in acute respiratory distress syndrome. Am J Respir Crit Care Med 1996;153(3):991-996.

7. Ferguson ND, Cook DJ, Guyatt GH, Mehta S, Hand L, Austin P, et al. High-frequency oscillation in early acute respiratory distress syndrome. N Engl J Med 2013;368(9):795-805.

8. Papazian L, Forel JM, Gacouin A, Penot-Ragon C, Perrin G, Loundou A, et al. Neuromuscular blockers in early acute respiratory distress syndrome. N Engl J Med 2010;363(12):1107-1116.

9. Steinberg KP, Hudson LD, Goodman RB, Hough CL, Lanken PN, Hyzy R, et al. Efficacy and safety of corticosteroids for persistent acute respiratory distress syndrome. N Engl J Med 2006;354(16): 1671-1684.

10. Anzueto A, Baughman RP, Guntupalli KK, Weg JG, Wiedemann HP, Raventós AA, et al. Aerosolized surfactant in adults with sepsisinduced acute respiratory distress syndrome. Exosurf Acute Respiratory Distress Syndrome Sepsis Study Group. N Engl J Med 1996; 334(22):1417-1421. 
11. Collins SR, Blank RS. Approaches to refractory hypoxemia in acute respiratory distress syndrome: current understanding, evidence, and debate. Respir Care 2011;56(10):1573-1582.

12. ARDS Definition Task Force, Ranieri VM, Rubenfeld GD, Thompson BT, Ferguson ND, Caldwell E, et al. Acute respiratory distress syndrome: the Berlin Definition. JAMA 2012;307(23):2526-2533.

13. Kollef MH, Napolitano LM, Solomkin JS, Wunderink RG, Bae IG, Fowler VG, et al. Health care-associated infection (HAI): a critical appraisal of the emerging threat-proceedings of the HAI Summit. Clin Infect Dis 2008;47(Supp 2):S55-S99.

14. Knaus WA, Draper EA, Wagner DP, Zimmerman JE. APACHE II: a severity of disease classification system. Crit Care Med 1985; 13(10):818-829.

15. Vincent JL, Moreno R, Takala J, Willatts S, De Mendonça A, Bruining $\mathrm{H}$, et al. The SOFA (Sepsis-related Organ Failure Assessment) score to describe organ dysfunction/failure. On behalf of the Working Group on Sepsis-Related Problems of the European Society of Intensive Care Medicine. Intensive Care Med 1996;22(7):707-710.

16. Taylor RW, Zimmerman JL, Dellinger RP, Straube RC, Criner GJ, Davis $\mathrm{K} \mathrm{Jr}$, et al. Low-dose inhaled nitric oxide in patients with acute lung injury: a randomized controlled trial. JAMA 2004;291(13): 1603-1609.

17. Michael JR, Barton RG, Saffle JR, Mone M, Markewitz BA, Hillier $\mathrm{K}$, et al. Inhaled nitric oxide versus conventional therapy: effect on oxygenation in ARDS. Am J Respir Crit Care Med 1998;157(5): 1372-1380

18. Dellinger RP, Zimmerman JL, Taylor RW, Straube RC, Hauser DL, Criner GJ, et al. Effects of inhaled nitric oxide in patients with acute respiratory distress syndrome: results of a randomized phase II trial. Crit Care Med 1998;26(1):15-23.

19. Troncy E, Collet JP, Shapiro S, Guimond JG, Blair L, Ducruet T, et al. Inhaled nitric oxide in acute respiratory distress syndrome: a pilot randomized controlled study. Am J Respir Crit Care Med 1998; 157(5 Pt 1):1483-1488.

20. Lundin S, Mang H, Smithies M, Stenqvist O, Frostell C. Inhalation of nitric oxide in acute lung injury: results of a European multicentre study. Intensive Care Med 1999;25(9):911-919.

21. Adhikari NK, Burns KE, Friedrich JO, Granton JT, Cook DJ, Meade MO. Effect of nitric oxide on oxygenation and mortality in acute lung injury: systematic review and metaanalysis. BMJ 2007; 334(7597):779.

22. Zwissler B, Kemming G, Habler O, Kleen M, Merkel M, Haller M, et al. Inhaled epoprostenol (PGI2) versus inhaled nitric oxide in adult respiratory distress syndrome. Am J Respir Crit Care Med 1996; 154(6 Pt 1):1671-1677.

23. Torbic H, Szumita PM, Anger KE, Nuccio P, LaGambina S, Weinhouse G. Inhaled epoprostenol vs inhaled nitric oxide for re- fractory hypoxemia in critically ill patients. J Crit Care 2013;28(5): 844-848.

24. Camporota L, Sherry T, Smith J, Lei K, McLuckie A, Beale R. Physiological predictors of survival during high-frequency oscillatory ventilation in adults with acute respiratory distress syndrome. Crit Care 2013;17(2):R40.

25. Pappalardo F, Pieri M, Greco T, Patroniti N, Pesenti A, Arcadipane $\mathrm{A}$, et al. Predicting mortality risk in patients undergoing venovenous ECMO for ARDS due to influenza A (H1N1) pneumonia: the ECMOnet score. Intensive Care Med 2013;39(2):275-281.

26. Pham T, Combes A, Rozé H, Chevret S, Mercat A, Roch A, et al. Extracorporeal membrane oxygenation for pandemic influenza $A$ (H1N1)-induced acute respiratory distress syndrome: a cohort study and propensity-matched analysis. Am J Respir Crit Care Med 2013; 187(3):276-285.

27. Murphy CV, Schramm GE, Doherty JA, Reichley RM, Gajic O, Afessa B, et al. The importance of fluid management in acute lung injury secondary to septic shock. Chest 2009;136(1):102-109.

28. National Heart, Lung, and Blood Institute Acute Respiratory Distress Syndrome (ARDS) Clinical Trials Network, Wiedemann HP, Wheeler AP, Bernard GR, Thompson BT, Hayden D, et al. Comparison of two fluid-management strategies in acute lung injury. N Engl J Med 2006;354(24):2564-2575.

29. Boyd JH, Forbes J, Nakada TA, Walley KR, Russell JA. Fluid resuscitation in septic shock: a positive fluid balance and elevated central venous pressure are associated with increased mortality. Crit Care Med 2011;39(2):259-265.

30. Maitland K, Kiguli S, Opoka RO, Engoru C, Olupot-Olupot P, Akech $\mathrm{SO}$, et al. Mortality after fluid bolus in African children with severe infection. N Engl J Med 2011;364(26):2483-2495.

31. Gong MN, Bajwa EK, Thompson BT, Christiani DC. Body mass index is associated with the development of acute respiratory distress syndrome. Thorax 2010;65(1):44-50.

32. Anzueto A, Frutos-Vivar F, Esteban A, Bensalami N, Marks D, Raymondos K, et al. Influence of body mass index on outcome of the mechanically ventilated patients. Thorax 2011;66(1):66-73.

33. De Jong A, Molinari N, Sebbane M, Prades A, Futier E, Jung B, et al. Feasibility and effectiveness of prone position in morbidly obese patients with ARDS: a case-control clinical study. Chest 2013;143(6): 1554-1561.

34. Afshari A, Brok J, Møller AM, Wetterslev J. Aerosolized prostacyclin for acute lung injury (ALI) and acute respiratory distress syndrome (ARDS). Cochrane Database Syst Rev 2010;(8):CD007733.

35. Guérin C, Reignier J, Richard JC, Beuret P, Gacouin A, Boulain T, et al. Prone positioning in severe acute respiratory distress syndrome. N Engl J Med 2013;368(23):2159-2168.

This article is approved for Continuing Respiratory Care Education credit. For information and to obtain your CRCE

(free to AARC members) visit www.rcjournal.com 